\title{
Avaliação de vida útil econômica do ativo imobilizado do setor avícola
}

\section{Fixed assets economic useful life valuation on aviculture industry}

\section{Recebimento: 15/08/2020 - Aceite: 20/12/2021 - Publicação: 01/09/2021 \\ Processo de Avaliação: Double Blind Review}

\section{Andréa Soares da Silva}

Mestre em Contabilidade e Atuária pela Pontífica Univeridade Católica de Campinas(PUC-SP), Brasil

andreasoares94@gmail.com

https://orcid.org/0000-0001-6581-3895

\section{Ricardo Bagni Roveri}

Mestre em Contabilidade pela Pontífica Univeridade Católica de SP (PUC-SP), Brasil rbroveri@yahoo.com.br https://orcid.org/0000-0002-4573-8557

\author{
Alexandre Gonzales \\ Doutor em Controladoria e Contabilidade pela Universidade de São Paulo (USP), Brasil \\ Professor do Mestrado em Ciências Contábeis, Controladoria e Finanças pela Pontíficia \\ Universidade Católica de São Paulo (PUCSP), Brasil \\ agonzales@pucsp.br \\ https://orcid.org/0000-0002-2778-6280
}

\section{José Carlos Marion}

Doutor em Contabilidade pela Universidade de São Paulo (USP)

Professor do Mestrado em Ciências Contábeis, Controladoria e Finanças pela Pontíficia Universidade Católica de São Paulo (PUC-SP)

jcmarion@usp.br

https://orcid.org/0000-0002-5641-6107

\section{RESUMO}

A contabilidade brasileira iniciou seu processo de convergência aos padrões internacionais de contabilidade com a criação do Comitê de Pronunciamentos Contábeis, que é o órgão responsável pela emissão e estudo dos pronunciamentos que são balizadores do processo. O processo inicial se deu pela lei 11.638/2007, e em decorrência das alterações introduzidas por ela, o Comitê de Pronunciamentos Contábeis emitiu o CPC 27, que trata especificamente do assunto Ativo 
Imobilizado, no qual um dos tópicos é sobre avaliação da vida útil econômica para fins de depreciação. O presente artigo buscou responder a seguinte pergunta: as empresas do setor de avicultura no Brasil, estão aplicando o conteúdo do CPC 27 - Ativo Imobilizado, a respeito do conceito de vida útil econômica para fins de cálculo da depreciação? A pesquisa consistiu em conectar a prática, utilizando os questionários respondidos pelas empresas do setor avícola, avaliando o objetivo da aplicação do conceito de vida útil econômica para fins de depreciação, atrelado ao uso do ativo em função da sua condição de geração de benefícios econômicos para entidade que os controla, e utilizando também testes estatísticos para comparação das médias. O questionário apresentou indagações, a fim de identificar aplicação dos conceitos, vida útil média por subgrupos de ativo imobilizado, relevância do custo x benefício de sua aplicação, e impacto nas demonstrações. Apesar de mais de dois terços considerarem que a avaliação da vida útil econômica para fins de cálculo da depreciação tem efeito relevante nas demonstrações financeiras, sua aplicação prática não mostrou o mesmo nível.

Palavras-chave: vida útil econômica, CPC-27, ativo imobilizado, setor avicultura

\section{ABSTRACT}

The Brazilian accounting system started its convergence process to international accounting standards with the creation of the Accounting Pronouncements Committee, which is the entity responsible for issuing and studying the pronouncements guiding principles of the process. The initial process was based on the Law 11.638/2007, which included, among others the Fixed Assets, and as a result, the Accounting Pronouncements Committee issued CPC 27, which deals specifically with the subject Fixed Assets and one of its items establishes the concept of economic useful life for depreciation purposes. The present article aimed to answer the following question: Are companies in the poultry sector in Brazil applying the content of CPC 27 with respect to the concept of economic useful life for the purpose of depreciation calculation? The research consisted in connecting the practice, through questionnaires answered by the aviculture companies, the theory evaluating the objective of applying the concept of economic useful life for purposes of depreciation, linked to the use of the asset as condition to generate economic benefits to the controlling entity, and through statistics tests to compare both averages. The questionnaire performed questions in order identify the application of this concept, average useful life by subgroups of fixed assets, relevance of the cost $x$ benefit of the application and 
impact on financial statements. Although more than two/thirds consider that the assessment of economic useful lives for depreciation purposes has a significant effect on the financial statements, their practical application was not shown in the same level.

Keywords: economic useful life, CPC-27, fixed assets, aviculture segment

\section{INTRODUÇÃO}

De maneira geral, é muito ampla a discussão sobre a transparência e a qualidade das informações contábeis, segundo Iudícibus e Marion (2017, p.53), "(...) fornece informação estruturada de natureza econômica, financeira e, subsidiariamente, física, de produtividade e social, aos usuários internos e externos à entidade".

A motivação dessa pesquisa consiste na identificação da forma de mensuração da vida útil econômica de ativos imobilizados, o que contribui de forma bastante intensa na maneira que as empresas fornecem as informações contábeis, por parte das empresas do setor de avicultura, e se de fato esta forma diverge da normatização da Receita Federal para fins societários.

A contabilidade sempre foi muito influenciada pelos limites e critérios fiscais, particularmente os da legislação do Imposto de Renda. Este fato, ao mesmo tempo que trouxe à contabilidade algumas contribuições importantes e bons efeitos, limita a evolução dos Princípios Fundamentais de Contabilidade, ou ao menos, dificulta a adoção prática de princípios contábeis adequados, já que a contabilidade era feita pela maioria das empresas com base nos preceitos e formas de legislação fiscal, a qual nem sempre se baseava em critérios contábeis corretos (Iudícibus, 2017).

A questão de tornar a contabilidade societária de acordo com seus princípios geralmente aceitos, desvinculada da legislação fiscal, sempre existiu. Havia uma discussão por parte de entidades contábeis brasileiras, contadores, auditores, órgãos reguladores, dentre outros, sobre a necessidade de modernização da contabilidade local instituída pela Lei das Sociedades por Ações n. 6.404/1976, para torná-la equiparável com as necessidades das informações globais.

Com a Resolução CFC n ${ }^{\circ}$ 1.055/2005, foi criado o Comitê de Pronunciamentos Contábeis (CPC). Nesse sentido o CPC passou a revisar e discutir com entidades e comunidade contábil como um todo as normas emitidas pelo International Accounting Standard Board (IASB) referente às normas internacionais de contabilidade. Nesse sentido em 28 de dezembro de 2007 , 


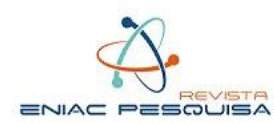

emitiu-se a Lei $\mathrm{n}^{\circ} 11.638$, o que proporcionaria a aproximação de normas contábeis brasileiras às internacionais. A vigência desta lei foi a partir de 01 de janeiro de 2008.

Em 26/06/2009 foi emitido pelo CPC o pronunciamento técnico sobre Ativo Imobilizado, modificando o modo de avaliação de um ativo imobilizado. Destaca-se o item 57 desse pronunciamento, que trata de critérios de depreciação, conforme definição de vida útil. Mesmo anteriormente à publicação desse pronunciamento técnico, já havia uma Resolução do Conselho Federal de Contabilidade sobre a definição de vida útil econômica.

Assumindo isto, o presente trabalho de caráter descritivo, propõe responder o seguinte problema de pesquisa: como está sendo a aplicação por parte das empresas não listadas do setor de avicultura quanto à aplicação do pronunciamento técnico CPC 27 em relação ao conceito de vida útil econômica? A importância de responder essa questão refere-se ao fato de que se a empresa estiver utilizando o CPC 27 no quesito de avaliação de vida útil econômica, as demonstrações contábeis refletem a representação fidedigna da realidade, e dessa forma representam informação útil para tomada de decisão ao usuário da informação.

O artigo apresenta por objetivo a elaboração de uma análise da aplicação da vida útil considerada para ativos imobilizado, no intuito de evidenciar a aplicação da norma pelas empresas não listadas do setor de avicultura, sob o ponto de vista de qualidade e relevância da informação e sua comparabilidade.

Levando-se em conta que em muitas empresas o ativo imobilizado tem representação considerável na composição do valor total do ativo, seu tratamento pode impactar significantemente a análise do lucro. Espera-se contribuir com a temática da pesquisa das empresas não listadas em bolsa, estudadas do setor avícola, com a finalidade de entender a relevância dos impactos nas demonstrações financeiras na visão do profissional contábil, que a adoção da norma pode trazer. Ademais, pretende-se demonstrar se houve aplicação adequada do Pronunciamento Técnico CPC 27 - Ativo Imobilizado no tocante à definição de vida útil econômica do ativo para depreciação, e se essa informação é relevante para efeitos de comparabilidade no setor. 


\section{REFERENCIAL TEÓRICO}

\subsection{Ativo Imobilizado conceito e normatização}

O tratamento contábil a ser utilizado para ativo imobilizado tem como base o Pronunciamento Técnico CPC 27 - Ativo Imobilizado, mais especificamente contabilização do imobilizado, seu reconhecimento, determinação de valores contábeis, e depreciação e perdas por desvalorização.

Ativo é definido como a representação de benefícios econômicos futuros prováveis, em decorrência de eventos passados, obtidos ou controlados por uma entidade (Hendriksen, \& Van Breda, 1999).

Iudícibus (2017, p.125) define como característica fundamental do ativo "trazer benefícios imediatos ou futuros, onde transformará esses benefícios em entradas liquidas de caixa ou economia de saídas liquidas de caixa".

Saber definir e conceituar corretamente o ativo é muito importante, pois ele está ligado diretamente com relacionamentos de receitas e despesas.

O Ativo Imobilizado é definido como sendo item tangível que:

a) É mantido para uso na produção ou fornecimento de mercadorias ou serviços, para aluguel a outros, ou para fins administrativos; $\mathrm{e}$

b) Se espera utilizar por mais de um período.

(Pronunciamento Técnico CPC 27, 2009, p.3)

Gelbcke, Santos, Iudícibus e Martins (2018) entendem que no grupo de contas do ativo imobilizado, devem ser incluídos todos os bens de permanência duradoura, destinados ao funcionamento normal da sociedade e de seu empreendimento, assim como os direitos exercidos com essa finalidade. Como exemplos incluem-se nesse grupo: terrenos, máquinas e equipamentos, móveis e utensílios, benfeitorias em imóveis de terceiros, etc.

O custo de um ativo imobilizado deve ser reconhecido como ativo se, e apenas se:

c) For provável que futuros benefícios econômicos associados ao item fluirão para a entidade, e

d) O custo do item puder ser mensurado confiavelmente.

e) (Pronunciamento Técnico CPC 27 - Ativo Imobilizado, 2009, p.4.) 


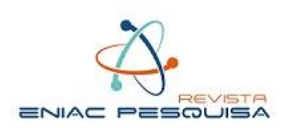

O imobilizado tangível talvez seja a melhor representação da capacidade instalada (ou da capacidade produtiva), principalmente em uma entidade manufatureira, podendo ter significação bem mais modesta em uma entidade bancária em outras atividades (Iudícibus, 2017).

\subsection{Processo de mensuração e atribuição de valor}

Em referência a uma definição do Comitê de Conceitos Contábeis e Padrões da AAA American Accounting Association, 1957, que "Conceitualmente, a medida de valor de um ativo é a soma dos preços futuros de mercado dos fluxos de serviços a serem obtidos, descontados pela probabilidade de ocorrência e pelo fator juro, a seus valores presentes". (Iudícibus, 2017, p.126).

Um ativo imobilizado no reconhecimento inicial deve ser mensurado pelo seu custo que pode ser considerado como sendo:

a) Seu preço de aquisição, acrescido de impostos de importação e impostos não recuperáveis sobre a compra, depois de deduzidos os descontos comerciais e abatimentos;

b) Quaisquer custos diretamente atribuíveis para colocar o ativo no local e condição necessárias para o mesmo ser capaz de funcionar de forma pretendida pela administração;

c) A estimativa inicial dos custos de desmontagem e remoção do item e de restauração do local (sítio) no qual está localizado. Tais custos representam a obrigação em que a entidade incorre quando o item é adquirido ou, como consequência de usá-lo durante determinado período para finalidades diferentes da produção de estoque durante esse período.

(Pronunciamento Técnico CPC 27 - Ativo Imobilizado, 2009, p.5)

Dornelles (2011) analisou os reflexos do novo tratamento contábil dos investimentos em ativo imobilizado CPC27. Por meio de pesquisa empírica de conteúdo bibliográfico, destaca que investimentos em ativo imobilizado são expressivos e ressalta necessidade de especialização e busca de conhecimento do profissional contábil.

Gelbcke et al (2018) definem que o custo do ativo imobilizado é limitado pelo valor, pelo uso (ou venda para ativos destinados a esse fim) e possa ser obtido em termos de fluxos de caixa futuros. Logo, o custo do ativo deve ser no máximo igual ao valor presente dos fluxos de caixa líquidos futuros decorrentes, direta ou indiretamente, do uso (ou venda) deste. 


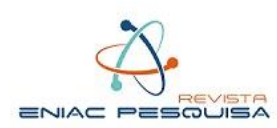

Entende-se, portanto, que um ativo imobilizado não pode estar registrado por um valor superior àquele que aplicado na prestação de serviços. Nesse sentido, diante dessa situação, a entidade deve proceder ao teste de recuperabilidade do ativo. Em casos nos quais o valor contábil exceda o valor de recuperação, deve ser constituída uma estimativa para perda do valor recuperável, com contrapartida diretamente em conta de resultado.

\subsection{Depreciação}

Com exceção dos terrenos e de alguns outros itens, os elementos que integram o Ativo Imobilizado têm um período limitado de vida útil econômica, ou seja, uma certa limitação na sua capacidade de gerar benefícios econômicos futuros para a empresa que os controla, pelo uso e pelo desgaste.

Marion (2014) afirma que poderá ser computada como custos (despesas), em cada exercício, a importância correspondente à diminuição do valor dos bens do ativo imobilizado resultante dos desgastes pelo uso, ação da natureza e obsolescência.

A depreciação diz respeito à perda de valor dos direitos que tem por objeto bens físicos sujeitos a desgastes ou perda de utilidade por uso, ação da natureza ou obsolescência (Schmidt, Santos, \& Gomes, 2003).

Embora essa definição contida no texto do Pronunciamento Técnico CPC 27, a resolução do Conselho Federal de Contabilidade (CFC) 1.027/05 já estabelecia critérios e procedimentos para registro contábil da depreciação, amortização e exaustão de ativos de natureza permanente. Em relação à definição de vida útil e conceito para sua estimativa, a resolução trazia em seu item 19.5.5.1:

Os seguintes fatores devem ser considerados ao se estimar a vida útil, período de uso e volume de produção de um ativo:

a) o uso esperado do ativo, que deve ser avaliado com base na capacidade esperada ou na produção física do ativo;

b) o desgaste físico esperado, que depende de fatores operacionais, tais como o número de turnos durante os quais o ativo será usado, o programa de reparo e manutenção, inclusive enquanto estiver ocioso;

c) a obsolescência tecnológica resultante de mudanças ou aperfeiçoamentos na produção ou mudanças na demanda no mercado pelo produto ou serviço produzido pelo ativo; e 


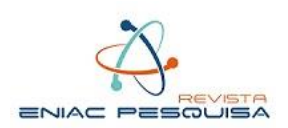

d) os limites legais ou semelhantes sobre o uso do ativo, tais como datas de expiração dos respectivos arrendamentos, permissões de exploração ou concessões. (NBC T 19.5 Depreciação, Amortização e Exaustão, 2005)

Souza (2013) fez um levantamento da vida útil antes e após aplicação do Pronunciamento Técnico 27 no período de 2007 a 2012, em 16 empresas listadas na BM\&FBovespa, e verificou diferenças significativas para amostra.

Zanella e Sembraneli (2016) fizeram um estudo da aplicação do Pronunciamento Técnico CPC 27 pelos escritórios de contabilidade de Quilombo SC. A amostra foi composta por 3 escritórios, e verificou-se com utilização de questionários enviados, que apenas 33\% estavam aplicando o conteúdo da norma, justificando uma vantagem em relação à legislação fiscal utilizada anteriormente, o que poderia ser um problema caso as empresas não estivessem embasadas tecnicamente com laudos de avaliação.

\subsection{Importância da definição do método para qualidade contábil}

Faz-se importante estabelecer a distinção entre utilidade e relevância da contabilidade. A contabilidade pode ser útil de três formas: fornece métricas para estabelecimento de metas; subsidiar a compreensão e o monitoramento de fenômenos; e subsidiar a tomada de decisões (Hendriksen, \& Van Breda, 1999).

Hendriksen e Van Breda (1999) apresentam algumas situações, tais como a avaliação dos ativos e sua depreciação, nas quais, utilizando os padrões internacionais de contabilidade, é possível optar por mais de uma alternativa de reconhecimento do mesmo fato contábil, afetando o resultado da empresa, ora aumentando-o, ora diminuindo-o.

Barth, Beaver e Landsman (2001) destacam que este tipo de pesquisa avalia o quanto as informações contábeis refletem as informações utilizadas por investidores na formação do preço das ações e fornece subsídios sobre questões de interesse para o normatizado.

O grau de competição do mercado afeta tanto as decisões operacionais como as decisões contábeis. Por exemplo, Hou e Robinson (2006) exploram como os determinantes da competição no mercado, medido pelo índice de concentração (também chamado do índice de Herfindahl), afetam o mercado de capitais medido pelo retorno das ações. 


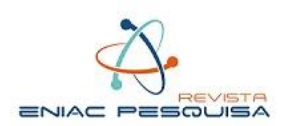

Esse embasamento teórico destaca bem a importância do assunto abordado neste artigo. É necessário saber como a empresa está alocando em seus custos as depreciações de equipamentos, máquinas, benfeitorias, etc., considerando que o método escolhido pode ser parcela fictícia favorável ao lucro.

\section{METODOLOGIA}

O trabalho foi desenvolvido partindo de estudo bibliográfico, utilizando livros, leis e artigos já publicados sobre o tema. Foi aplicado o método descritivo utilizando metodologia de coleta de dados primários com a aplicação de questionário direcionado à área contábil das empresas de avicultura não listadas.

Conforme Oliveira (2011), a metodologia é o estudo do método e de suas técnicas. O estudo pode ser caracterizado como descritivo, e pode ser o meio no qual são expostas características de determinada população ou determinado fenômeno (VERGARA, 2016).

O ponto inicial do trabalho foi identificação do referencial teórico do ativo imobilizado, processo de mensuração e depreciação, conforme a literatura, normatização, publicações de pesquisas recentes sobre aplicação geral e específica, com a finalidade de identificar a aplicação do conteúdo do Pronunciamento Técnico CPC 27 no que se refere ao conceito de vida útil econômica.

Na sequência foi feita uma pesquisa de campo utilizando um questionário elaborado com perguntas especificas, e enviado para empresas do segmento de avicultura, procedimento a ser detalhado a seguir.

Algumas perguntas foram elaboradas de acordo com alguns embasamentos teóricos que salientam a importância do assunto, apresentados na Tabela 1: 
Tabela 1: Embasamento teórico utilizado para elaboração das questões:

\begin{tabular}{|c|c|c|}
\hline Questões & Embasamento Téorico & Fonte Citada \\
\hline $\begin{array}{l}\text { 3) Você tem conhecimento do } \\
\text { conteúdo do CPC } 27 \text { (Comite } \\
\text { de Pronunciamento Contábeis) } \\
\text { Ativo Imobilizado? }\end{array}$ & $\begin{array}{l}\text { A aplicação do conteúdo deste procunciamento tem impacto } \\
\text { direto nas demonstrações contábeis das empresas em especial à } \\
\text { avaliação da vida útil econômica para fins de depreciação. A } \\
\text { forma de sua adoção deve permitir à entidade que elabore e } \\
\text { apresente suas demonstrações contábeis de modo a representação } \\
\text { fidedigna da realidade. A maior dificuldade na convergência para } \\
\text { normas internacionais não é de conhecer as novas normas, mas } \\
\text { sim de mudança de postura, de comportamento. }\end{array}$ & $\begin{array}{l}\text { Norma CPC } 27 \quad-\quad \text { Ativo } \\
\text { Imobilizado }\end{array}$ \\
\hline $\begin{array}{l}\text { 4) Sua empresa optou pelo } \\
\text { método de avaliação de vida } \\
\text { util econômica } \\
\text { depreciação para } \\
\text { Imobilizado? } \\
\text { 5) Caso optante por "sim" qual } \\
\text { o método de Avaliação de } \\
\text { ativos para determinação da } \\
\text { vida útil Economica? }\end{array}$ & $\begin{array}{l}\text { Os bens do ativo imobilizado representam geralmente uma } \\
\text { parcela significativa dos ativos de uma empresa, principalmente } \\
\text { em indústrias, o que não é diferente no setor avícola. Esses bens } \\
\text { tem uma permanencia prolongada na companhia, não são } \\
\text { destinados a venda e são utilizados na manutenção das suas } \\
\text { atividades e geração de benefício econômico futuro pelo prazo } \\
\text { que espera-se utilizá-lo. A depreciação representa o desgaste do } \\
\text { bem pelo uso na geração de benefícios econômicos e afeta } \\
\text { diretamente o resultado do período. }\end{array}$ & $\begin{array}{l}\text { Norma CPC } 27 \\
\text { Imobilizado }\end{array}$ \\
\hline 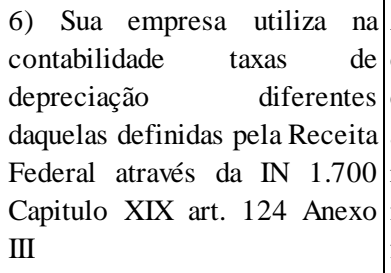 & $\begin{array}{l}\text { A Alteração de vida util de um bem tem impacto direto nas taxas } \\
\text { de depreciação que por consequência sua alocação ao resultado } \\
\text { como despesa, afetam o lucro tributável. Esse efeito pode trazer } \\
\text { aumento ou redução do lucro e do valor a recolher de imposto de } \\
\text { renda pessoa juridica (IRPJ). Ajustes são requeridos afim de } \\
\text { neutralizar impacto da norma sobre lucro contábil para o lucro } \\
\text { fiscal como é o caso da diferença de taxas de depreciação. }\end{array}$ & $\begin{array}{l}\text { Artigo - "Efeito do regime } \\
\text { tributário de transição na carga } \\
\text { tributária das companhias } \\
\text { braliseiras", publicado em } 2013 . \\
\text { Autores: Helio Rieger de Mello e } \\
\text { Bruno Meirelles Salotti }\end{array}$ \\
\hline $\begin{array}{l}\text { 7) Qual vida útil aplicada na sua } \\
\text { empresa por grupo de ativo } \\
\text { Imobilizado para fins de } \\
\text { aplicação do CPC } 27 \text { - Ativo } \\
\text { Imobilizado e para fins fiscais } \\
\text { conforme IN } 1.700 \text { de } 2017 \\
\text { Capítulo XIX art.124 Anexo } \\
\text { III? }\end{array}$ & $\begin{array}{l}\text { A vida util esta relacionada ao tempo esperado em que o bem seja } \\
\text { útil às operações da empresa e sua estimativa baseia-se na analise } \\
\text { de bens semelhantes que esta possua em seu imobilizado, } \\
\text { seguindo as determinações do CPC } 27 \text { (Moraes, 2010). } \\
\text { Já o valor residual consiste no valor esperado de venda do ativo } \\
\text { ao final de sua vida útil, quando não será mais utilizado pela } \\
\text { empresa (PÊGAS, 2010). A depreciação representa a parcela } \\
\text { alocada ao resultado decorrente do desgaste pelo uso do bem e a } \\
\text { a definição correta de vida útil econômica tem impacto direto na } \\
\text { determinação do lucro líquido e por consequência representação } \\
\text { verdadeira. }\end{array}$ & $\begin{array}{l}\text { Citação no artigo - "Impacto da } \\
\text { adoção do CPC } 27 \text { na } \\
\text { depreciação contábil das } \\
\text { empresas listadas nos setores de } \\
\text { bens industriais e de transportes } \\
\text { da Bovespa" publicado em } 2015 . \\
\text { Autores: Paola Oliveira, Fabrício } \\
\text { Afonso de Souza, Mônica de } \\
\text { Oliveira Costa e Farana de } \\
\text { Oliveira Mariano }\end{array}$ \\
\hline $\begin{array}{l}\text { 8) Qual o método de apuração } \\
\text { de Imposto de Renda? }\end{array}$ & $\begin{array}{l}\text { O Imposto de Renda tem sua origem na Lei } 4625 \text { de } 31 \text { de } \\
\text { dezembro de } 1922 \text {, que orçou a receita geral da República para o } \\
\text { exercício de } 1923 \text {, é o tributo de maior importância não só no } \\
\text { tocante ao volume de arrecadação, mas também, como um } \\
\text { poderoso instrumento do qual o Governo procura promover a } \\
\text { melhor distribuição de renda no país, bem como o } \\
\text { desenvolvimento econômico de determinadas regiões } \\
\text { geográficas e de determinadas atividades econômicas, através de } \\
\text { programas de incentivos fiscais (Camargo, } 1997 \text { p.105) }\end{array}$ & $\begin{array}{l}\text { Dissetação de Mestrado - A } \\
\text { importância da Contabilidade no } \\
\text { processo de decisão entre o } \\
\text { Lucro Real e Lucro Presumido }\end{array}$ \\
\hline $\begin{array}{l}\text { 9) Sua empresa ajusta } \\
\text { diferenças de depreciação pela } \\
\text { adoção do CPC } 27 \text { e para fins } \\
\text { fiscais na apuração de Imposto } \\
\text { de Renda e Contribuição Social } \\
\text { na Escrituração Contábil e } \\
\text { Fiscal (ECF) }\end{array}$ & $\begin{array}{l}\text { A adoção das normas internacionais de contabilidade teve } \\
\text { impacto relevante no lucro das empresas. A adoção do conceito } \\
\text { de vida útil econômica para depreciação pode gerar diferenças } \\
\text { relevantes entre as taxas fiscais e seus impactos observados com } \\
\text { atenção pelas empresas pois pode haver aumento ou redução do } \\
\text { lucro e do valor a recolher de imposto de renda pessoa juridica } \\
\text { (IRPJ), valores esses que devem ser ajustados afim de respeitar } \\
\text { preceitos da legislação fiscal definidos (taxas fiscais). }\end{array}$ & $\begin{array}{l}\text { Artigo - "Efeito do regime } \\
\text { tributário de transição na carga } \\
\text { tributária das companhias } \\
\text { braliseiras", publicado em } 2013 . \\
\text { Autores: Helio Rieger de Mello e } \\
\text { Bruno Meirelles Salotti }\end{array}$ \\
\hline
\end{tabular}




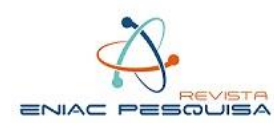

\begin{tabular}{|c|c|c|}
\hline 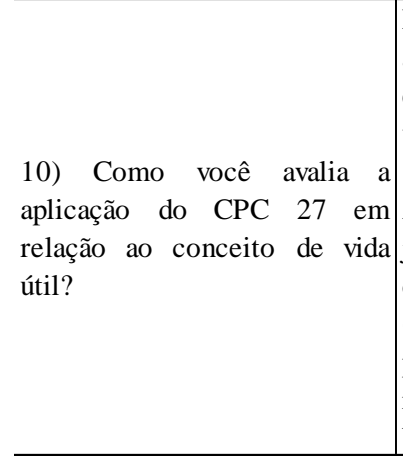 & $\begin{array}{l}\text { Essa vida útil é representada pela figura da depreciação, que é a } \\
\text { alocação do custo do imobilizado de forma sistemática nos } \\
\text { exercícios que forem beneficiados pelo seu uso, ao longo dessa } \\
\text { vida útil (CPC 27; MARTINS et al., 2013). } \\
\text { A estimativa da vida útil do ativo é, assim, uma questão de } \\
\text { julgamento. Devido à subjetividade dessa avaliação, ela pode ser } \\
\text { determinada considerando o lucro ao qual a empresa quer chegar } \\
\text { (BAPTISTA, 2009). O conceito de vida útil é importante pois } \\
\text { permite a representação fidedigna da alocação de depreciação ao } \\
\text { resultado pelo efetivo uso até que se pretenda usufruir dos } \\
\text { benefícios de determinado ativo. }\end{array}$ & $\begin{array}{l}\text { Artigo: Divulgação da informação } \\
\text { contábil sobre a depreciação: } \\
\text { Antes e o depois da Adoção IFRS. } \\
\text { Publicado em 2015. Autores: } \\
\text { Samanntha Valentim Telles e } \\
\text { Bruno Meirelles Salotti }\end{array}$ \\
\hline
\end{tabular}

Fonte: Elaborado pelos autores.

\subsection{Amostra}

A amostra da pesquisa foi composta por empresas do setor avícola de frangos de corte, tomando como base a listagem de clientes ativos de uma empresa fornecedora de aves matrizes para produção desses frangos que detém aproximadamente $35 \%$ do volume do mercado livre, e estima-se que atende aproximadamente $70 \%$ dos clientes ativos do setor. O contato com os entrevistados se deu por meio de relacionamento comercial existente. A amostra correspondeu a empresas situadas nos Estados do Paraná, Ceará, Piauí, Minas Gerais, Pernambuco, Rio Grande do Sul, São Paulo, etc.

O envio do questionário e o acompanhamento das respostas, foram também suportados pelo time comercial da empresa fornecedora, auxiliando significativamente ao realizar contato com os responsáveis pelas empresas pesquisadas. Assim como pedindo autorização dos sócios das empresas para que as informações fossem compartilhadas, fornecendo suporte no preenchimento dos questionários por parte da área contábil.

Tabela 2: Quantidade de questionários enviado por estados e respondentes:

\begin{tabular}{ccccc}
\hline Estados & Envio & Resposta & Ignorados & Utilizados \\
\hline Bahia & 2 & 0 & & 0 \\
\hline Ceará & 2 & 1 & & 1 \\
\hline Goiás & 1 & 0 & & 0 \\
\hline Minas Gerais & 3 & 1 & & 1 \\
\hline Paraíba & 3 & 2 & 1 & 1 \\
\hline Pernambuco & 4 & 2 & 2 & 0 \\
\hline Piauí & 1 & 1 & & 1 \\
\hline Paraná & 12 & 6 & & 6 \\
\hline
\end{tabular}




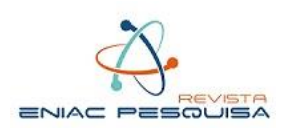

\begin{tabular}{ccccc}
\hline Rio Grande do Sul & 3 & 1 & & 1 \\
\hline Santa Catarina & 1 & 0 & & 0 \\
São Paulo & 7 & 4 & 1 & 3 \\
Tocantins & 1 & 0 & & 0 \\
Total & $\mathbf{4 0}$ & $\mathbf{1 8}$ & $\mathbf{4}$ & $\mathbf{1 4}$ \\
\hline & Fonte: Elaborado pelos autores &
\end{tabular}

\subsection{Limitação da pesquisa}

As amostras podem ser aleatórias ou não-aleatórias, e esse estudo se baseou na segunda opção. Há situações nas quais é muito difícil de se conseguir seleção por amostras aleatórias, ou até mesmo impossível, pois a maior limitação está na obtenção de uma lista de todos os elementos da população (Barbetta, 2014). Esse foi o caso, pois não foi possível obter uma listagem completa de todas as empresas do setor avícola no país em atividade no momento dessa pesquisa, o que poderia caracterizar uma amostra como aleatória e probabilística.

Foi utilizada a amostragem intencional para o presente estudo, caracterizada pelo direcionamento do investigador a grupos de empresas selecionados, a fim de se obter respostas. Por ser considerado um método de amostragem não probabilístico, não é possível generalizar os resultados dessa amostra para a população (Martins, \& Teóphilo, 2016).

A amostragem probabilística é preferida em relação à amostragem não-probabilística, mas em muitos cenários de investigação social não é possível, sob ponto de vista prático, ou até mesmo desejável pela limitação de tempo e custos. (Maroco, 2010).

Não foi possível garantir com segurança que a base de dados utilizada para envio dos questionários represente todos os clientes do setor avícola em atividade na data dessa pesquisa, com a finalidade de garantir $100 \%$ de chance de participação. Desse modo a amostra não pode ser caracterizada como aleatória e isso impõe limitações ao estudo o que impossibilita a realização de inferências para toda população.

\subsection{Base de dados para pesquisa}

O questionário, que é um conjunto ordenado e consistente de perguntas relacionadas a variáveis e situações que se pretende descrever ou medir, representa um importante e popular instrumento de coleta de dados para uma pesquisa social (Martins, \& Teóphilo, 2016).

Ao proceder a coleta de dados, foram verificados pelo pesquisador dois tipos de variáveis, quantitativas e qualitativas. As quantitativas envolvem caráter numérico, e no presente estudo 


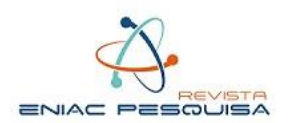

representaram a vida útil dos ativos imobilizados. As qualitativas apresentam maior dificuldade de mensuração por não tratar de valores numéricos e envolver certo grau de subjetividade.

Questionários apresentam algumas vantagens, como a possibilidade de atingir grande número de pessoas dispersas em áreas extensas, reduzidos gastos com pessoal por não exigir treinamento de pesquisadores, anonimato das respostas, possibilidade de se responder no momento mais conveniente, e não expõem os pesquisados à influência das opiniões de aspecto pessoal do entrevistador (Gil, 2008).

O questionário apresentou questões de múltipla escolha com objetivo direto de explorar respostas por "sim" ou "não" acerca do conhecimento do entrevistado sobre o tema, de identificar tamanho da empresa pelo faturamento e ativos totais, obter comparativo e análises sobre as respostas obtidas com a finalidade de identificar a aplicabilidade da norma com relação ao conceito de vida útil, se sua aplicação produziu efeitos relevantes nas demonstrações financeiras, sua importância com relação à comparabilidade, e sua aplicabilidade considerando-se os custos adicionais de controle.

Foram enviados um total de 40 questionários durante o mês de setembro e outubro de 2018 por meio de e-mails, e foram obtidas 18 respostas coletadas com utilização do hospedador Survey Monkey. Desse total foram desprezadas 4 respostas por terem respostas que não puderam ser consideradas consistentes, com baixo tempo dispendido para resposta, e também por conterem muitas perguntas ignoradas. Os dados foram tabulados no Excel evidenciados no quadro 1.

Em relação à definição de quais contas seriam base da pesquisa, fez-se a opção de dividir o imobilizado em subgrupos visando melhorar a qualidade de análise. Dessa forma obteve-se o subgrupo de ativo imobilizado conforme Tabela 3: 


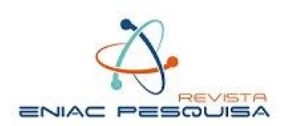

Tabela 3 - Subgrupos do imobilizado

\begin{tabular}{cl}
\hline Subgrupo & \multicolumn{1}{c}{ Composição } \\
\hline 1 & Máquinas e equipamentos \\
2 & Edifícios e construções \\
3 & Benfeitorias em propriedade \\
\hline 4 & Veículos \\
5 & Equipamentos de informática \\
6 & Instalações \\
7 & Móveis e utensílios \\
\hline & Fonte: Elaborado pelos Autores \\
\hline
\end{tabular}

O subgrupo 1 se refere a itens relacionados a maquinários agrícolas, equipamentos de granja e incubatórios. O subgrupo 2 se refere a edificações, estruturas de granjas, incubatórios parte hidráulica e parte elétrica, área administrativa, fábrica de ração. O subgrupo 3 se refere a benfeitorias em propriedades de terceiros, instalações hidráulicas e elétricas. O subgrupo 4 inclui veículos leves, caminhões e tratores $O$ subgrupo 5 inclui computadores, telefonia, impressoras, equipamentos de processamento de dados. O subgrupo 6 inclui instalações elétricas e hidráulicas. O subgrupo 7 inclui bens móveis.

\section{RESULTADOS E DISCUSSÕES}

O público-alvo que foi atingido pelo questionário foi constituído por profissionais da área contábil de empresas de avicultura não listadas, sendo que 73,68\% não autorizaram a divulgação da identificação. Foi selecionado conforme base em relacionamentos comerciais provenientes de atuação no segmento estudado. Foram desprezadas da base de dados empresas que publicam demonstrações financeiras.

A distribuição dos questionários foi feita por meio de mensagens eletrônicas (e-mails) contendo em seu corpo além da característica básica objeto da pesquisa, apresentação do pesquisador e a empresa fornecedora de aves que trabalha e link para acesso ao questionário hospedado em Survey Monkey. A seguir apresenta-se os resultados na Tabela 4:

Tabela 4: Questionário: Avaliação Vida Útil

Questões Aplicadas $\%$

Autoriza a identificação? 


\begin{tabular}{l|l} 
Sim & $28,5 \%$ \\
\hline Não & $71,4 \%$ \\
\hline
\end{tabular}

1) Qual faixa de faturamento anual de sua empresa, vide encerramento em 31/12/2017?
a)Até $\mathrm{R} \$ 300.000 .000$, $35,7 \%$
b)Acima $R \$ 300.000 .001$,

$64,3 \%$

2) Qual o Valor total dos ativos da sua empresa em 31/12/2017

\begin{tabular}{c|l}
\hline a)Até $\mathrm{R} \$ 240.000 .000$, & $50,0 \%$ \\
\hline b)Acima $\mathrm{R} \$ 240.000 .001$, & $50,0 \%$ \\
\hline
\end{tabular}

3) Você tem conhecimento do conteúdo do CPC 27 (Comitê de Pronunciamentos Contábeis) - Ativo Imobilizado?

\begin{tabular}{l|l}
\hline Sim & $100,0 \%$ \\
\hline Não & \\
\hline
\end{tabular}

4) Sua Empresa optou pelo método de avaliação de vida útil econômica para depreciação do Ativo Imobilizado?

\begin{tabular}{c|l}
\hline Sim & $57,1 \%$ \\
\hline Não & $42,9 \%$ \\
\hline
\end{tabular}

5) Caso Optante por "sim” qual método de avaliação de ativos para determinação de vida útil econômica

\begin{tabular}{l|l|l} 
a) Laudo elaborado por empresas externas. & $75,0 \%$
\end{tabular}

b) Laudo Elaborado por Profissionais técnicos. $\quad 25,0 \%$

\begin{tabular}{l|l}
\hline C) Outros especifique) & $0 \%$
\end{tabular}

6) Sua Empresa utiliza na contabilidade taxas de Depreciação diferentes daquelas definidas pela Receita

Federal através da IN 1.700 Capitulo XIX art. 124 Anexo III?

\begin{tabular}{c|l}
\hline Sim & $57,1 \%$ \\
\hline Não & $42,9 \%$ \\
\hline
\end{tabular}

7) Qual vida útil aplicada na sua empresa por grupo de ativo Imobilizado para fins de aplicação do CPC

27 - Ativo Imobilizado e para fins fiscais conforme IN 1.700 de 2017 Capítulo XIX art.124 Anexo III?

\begin{tabular}{c|l}
\hline Maquinas e Equipamentos & 15,4 anos \\
\hline Edifícios e Construções & 35,9 anos \\
\hline Benfeitorias em Propriedades & 29,0 anos \\
\hline Equículos & 8,4 anos \\
\hline Instalações & 6,3 anos \\
\hline M) Qual o método e Utensílios & 20,8 anos \\
\hline a) Lucro Real & 11,6 anos \\
\hline b) Lucro Presumido & $\mathbf{4 2 , 9 \%}$ \\
\hline
\end{tabular}


9) Sua Empresa ajusta diferenças de depreciação pela adoção do CPC 27 e para fins fiscais na apuração de Imposto de Renda e Contribuição Social na Escrituração Contábil e Fiscal (ECF)?

\begin{tabular}{c|l}
\hline Sim & $42,9 \%$ \\
\hline Não & $57,1 \%$ \\
\hline 10) Como você avalia a aplicação do CPC 27 em relação ao conceito de vida útil? responda SIM ou NÃO
\end{tabular}

a) A mudança na estimativa da vida útil de ativo em comparação com taxas de depreciação definidas pela RFB tem efeitos relevantes no Balanço e DRE da sua empresa?

\begin{tabular}{c|l}
\hline Sim & $71,4 \%$ \\
\hline Não & $28,6 \%$ \\
\hline
\end{tabular}

b) Para sua empresa é relevante estimar um valor residual para ativos ao final de sua vida útil estimada?

\begin{tabular}{c|l}
\hline Sim & $50,0 \%$ \\
\hline Não & $50,0 \%$ \\
\hline
\end{tabular}

c) O custo e controle adicionais dessa aplicação na sua empresa superam os benefícios gerados?

\begin{tabular}{l|l}
\hline Sim & $7,1 \%$ \\
\hline Não & $92,9 \%$ \\
\hline
\end{tabular}

d) Você acredita que sua não aplicação pode afetar a comparabilidade das demonstrações Financeiras entre empresas do setor?

\begin{tabular}{c|l}
\hline Sim & $71,4 \%$ \\
\hline Não & $28,6 \%$ \\
\hline
\end{tabular}

Fonte: Elaborado pelos autores

Das empresas que compuseram a base da pesquisa em sua maioria, 64,3\% são qualificadas como empresas de grande porte pelo total de faturamento, acima de $\mathrm{R} \$ 300$ milhões anuais (dados de 2017). Concomitantemente, $50 \%$ dessas empresas por possuírem ativos totais superiores a $\mathrm{R} \$$ 240 milhões em 31/12/2017 são qualificadas como empresas de grande porte também por este critério. A definição de empresa de grande porte está prevista na Lei no $11.638 / 2007$ no artigo $3^{\circ}$.

Como esperado, importante o fato de que todos os entrevistados da área contábil dessas empresas independente do seu porte, tem ao menos algum tipo de conhecimento do conteúdo do Pronunciamento Técnico CPC 27 - Ativo Imobilizado e sua aplicabilidade. Em relação à aplicabilidade do método de avaliação de vida útil econômica do imobilizado para fins de cálculo e apropriação da despesa de depreciação, 51,7\% das empresas adotam essa estimativa. Esse índice representa uma maioria em relação às empresas classificadas como sendo de grande porte, obrigadas a realizar auditorias das demonstrações financeiras.

Do total dessas empresas que optam pela avaliação de vida útil econômica de ativo imobilizado, $75 \%$ utilizaram de empresas técnicas especializadas para elaboração dos laudos de 
avaliação, enquanto $25 \%$ se utilizaram de profissionais técnicos internos para elaboração dos laudos.

Ao se indagar sobre a utilização de taxas de depreciação diversas das taxas estabelecidas pela Receita Federal, assim como ocorreu como as respostas da questão de $n^{\circ} 4,42,9 \%$ dos respondentes declararam não o fazer.

Em relação aos dados obtidos pelo questionamento da vida útil econômica para ativo imobilizado aplicada pelas empresas que utilizam desse método, a maioria das respostas foram preparadas utilizando range numéricos ou vida útil média.

Analisando-se os dados em relação às taxas fiscais permitidas, o subgrupo de Máquinas e Equipamentos apresentou vida útil econômica média de 15 anos e 4 meses face aos 10 anos definidos pela Receita Federal. Da mesma forma o subgrupo de Edifícios e Construções apresentou vida útil média de 35 anos e 9 meses face aos 25 anos permitidos pela Receita Federal. O subgrupo de benfeitoria em propriedade de terceiro apresentou resultado de 29 anos em comparação com 25 anos permitidos pela legislação. O subgrupo de veículos obteve resultado médio de 8 anos e 4 mesespara depreciação por vida útil em comparação com 5 anos definidos pela legislação fiscal. O subgrupo de equipamentos de informática apresentou vida útil média de 6 anos e 3 meses em comparação com os percentuais divulgados pela Receita Federal que correspondem a 5 anos. O subgrupo de instalações hidráulicas e elétricas apresentou resultado de vida útil econômica de 20 e 8 meses anos em comparação com 10 anos definidos pela Receita Federal e por último o subgrupo de móveis e utensílios apresentou vida útil econômica média de 11 anos e 6 meses, muito próxima à taxa definida pela Receita Federal de 10 anos.

Da amostra selecionada, 100\% das empresas são tributadas pelo Lucro Real e de alguma forma estão sujeitas à ajustes permanentes e/ou temporários no LALUR (Livro de Apuração do Lucro Real).

Em relação ao ajuste da diferença da depreciação pelo método de avaliação de vida útil econômica e pelas taxas fiscais, $57,1 \%$ das empresas pesquisadas não ajustam esses valores na Escrituração Contábil Fiscal (ECF). Esse número é maior do que a proporção de empresas indicadas no item 4 que afirmaram fazer uso da avaliação da vida útil econômica, ou seja, podem estar considerando os laudos técnicos aprovados pela Receita Federal como base de justificativa ao fisco se questionados em algum momento, ou pode ser uma falha dessas empresas no ajuste da apuração do lucro fiscal, fato este, não capturado pelo questionário. Cabe ressaltar que na maioria das observações individuais, o prazo de vida útil pela vida econômica do bem é maior 


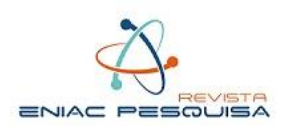

do que o prazo permitido pela legislação fiscal, resultando, assim, em maior parte dos casos, em uma taxa de depreciação menor.

Por fim, como esperado, $71,4 \%$ dos entrevistados responderam que a mudança de estimativa da depreciação pela vida útil em relação à taxa fiscal definida pela Secretaria da Receita Federal, tem impacto relevante em suas demonstrações financeiras. Em relação a estimar um valor residual do bem ao final da vida útil econômica, metade das empresas afirmaram ser relevante fazê-lo. Curiosamente, 92,9\% dos entrevistados afirmaram que o custo adicional de implantação e controle da estimativa de vida útil econômica para depreciação do ativo imobilizado não supera os benefícios gerados, e 71,4\% acreditam que a não aplicação desse conceito, ou seja, a manutenção das taxas fiscais para cálculo da depreciação, não afeta a comparabilidade das demonstrações financeiras do setor.

\subsection{ANÁLISE DA NORMALIDADE E TESTE DE WILCOXON}

\subsubsection{TESTE DE NORMALIDADE}

Ao final do processamento de análise de dados foi feito um teste estatístico com a finalidade de responder com segurança se existiram diferenças significativas entre a vida útil econômica praticada pelas empresas e aquelas definidas pela Receita Federal na amostra das empresas do setor de avicultura. Antes da definição do modelo de teste, foi verificada a normalidade das amostras com utilização do teste de Shapiro Wilk, demonstrado ns Tabela 4. Para o teste dos subgrupos foi adotado $5 \%$ ou $(\mathrm{a}=5 \%)$ que corresponde ao limite máximo para rejeitar a hipótese nula que significa que a amostra tem distribuição normal. Dessa forma se o $p$-value obtido da análise for < a, então rejeita-se a hipótese nula. Caso contrário, se $p$-value for $>$ a, aceita-se a hipótese nula. O sistema utilizado para o processamento deste teste foi o IBM SPSS Statistics. 


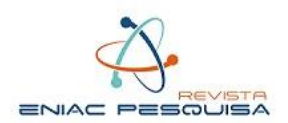

Tabela 5 - Teste de normalidade Shapiro Wilk

\begin{tabular}{|l|r|r|r|}
\hline Subgrupo Composição & Estatistica & df & Sig. P-Value \\
\hline 1 - Maquinas e equipamentos & 0,765 & 14 & 0,002 \\
\hline - Edificios e contruções & 0,716 & 14 & 0,001 \\
\hline 3 - Benfeitorias em propriedades & 0,741 & 14 & 0,001 \\
\hline 4 - Veículos & 0,713 & 14 & 0,001 \\
\hline 5 - Equipamentos de informática & 0,57 & 14 & 0,000 \\
\hline - Instalações & 0,837 & 14 & 0,015 \\
\hline 7 - Móveis e utensílios & 0,627 & 14 & 0,000 \\
\hline
\end{tabular}

Fonte: Elaborado pelos autores

Os valores do p-value apresentados para todos os subgrupos foi inferior a 0,05 , não aceitando assim a hipótese nula, significando que a distribuições das amostras testadas não pode ser considerada normal. Desta maneira, deve ser aplicado um teste de comparação de média classificado como não paramétrico.

\subsubsection{Teste de Wilcoxon ou de sinais}

Como observou-se essa amostra não possui distribuição normal. Portanto, optou-se por utilizar o teste estatístico de Wilcoxon, com objetivo de evidenciar se as variáveis vida útil econômica e taxa fiscal são significativamente diferentes. Esse teste, entre outras atribuições, calcula o $p$-value da distribuição que representa a probabilidade de erro da amostra. Se o p-value for menor que o nível de significância admitido, não se aceita a hipótese nula, comprovando-se que as médias obtidas não são iguais. O teste de Wilcoxon foi calculado para cada subgrupo de ativo imobilizado estudado na pesquisa pelo sistema IBM SPSS Statistics.

Foram realizados os testes de Wilcoxon em todos os grupos de ativos conforme tabela a seguir, os dados para os testes foram extraídos dos questionários aplicados com retornos válidos, conforme Tabela 6: 
Tabela 6 - Teste de Wilcoxon

\begin{tabular}{|c|c|c|c|c|}
\hline Categoria & Hipótese Nula & Teste & Sig. & Decisão \\
\hline 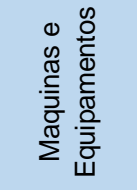 & $\begin{array}{l}\text { A Mediana das diferenças entre } \\
{ }^{1} \text { VAR00001 e VAR00002 é igual a } 0\end{array}$ & $\begin{array}{l}\text { Teste dos Postos Sinalizados de } \\
\text { Wilcoxon de Amostras Relacionadas }\end{array}$ & 0,016 & $\begin{array}{l}\text { Rejeitar a Hipótese } \\
\text { nula }\end{array}$ \\
\hline 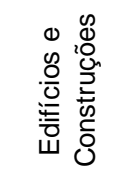 & $\begin{array}{l}\text { A Mediana das diferenças entre } \\
\text { VAR00001 e VAR00002 é igual a } 0\end{array}$ & $\begin{array}{l}\text { Teste dos Postos Sinalizados de } \\
\text { Wilcoxon de Amostras Relacionadas }\end{array}$ & 0,016 & $\begin{array}{l}\text { Rejeitar a Hipótese } \\
\text { nula }\end{array}$ \\
\hline 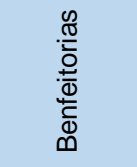 & $\begin{array}{l}\text { A Mediana das diferenças entre } \\
{ }^{1} \text { VAR00001 e VAR00002 é igual a } 0\end{array}$ & $\begin{array}{l}\text { Teste dos Postos Sinalizados de } \\
\text { Wilcoxon de Amostras Relacionadas }\end{array}$ & 0,345 & $\begin{array}{l}\text { Reter a Hipótese } \\
\text { nula }\end{array}$ \\
\hline $\begin{array}{l}\frac{0}{7} \\
\frac{0}{0} \\
\stackrel{0}{10}\end{array}$ & $\begin{array}{l}\text { A Mediana das diferenças entre } \\
\text { VAR00001 e VAR00002 é igual a } 0\end{array}$ & $\begin{array}{l}\text { Teste dos Postos Sinalizados de } \\
\text { Wilcoxon de Amostras Relacionadas }\end{array}$ & 0,078 & $\begin{array}{l}\text { Reter a Hipótese } \\
\text { nula }\end{array}$ \\
\hline 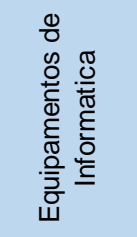 & $\begin{array}{c}\text { A Mediana das diferenças entre } \\
\text { VAR00001 e VAR00002 é igual a } 0\end{array}$ & $\begin{array}{l}\text { Teste dos Postos Sinalizados de } \\
\text { Wilcoxon de Amostras Relacionadas }\end{array}$ & 0,194 & $\begin{array}{l}\text { Reter a Hipótese } \\
\text { nula }\end{array}$ \\
\hline 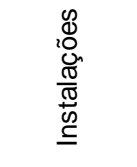 & $\begin{array}{l}\text { A Mediana das diferenças entre } \\
\text { VAR00001 e VAR00002 é igual a } 0\end{array}$ & $\begin{array}{l}\text { Teste dos Postos Sinalizados de } \\
\text { Wilcoxon de Amostras Relacionadas }\end{array}$ & 0,324 & $\begin{array}{l}\text { Reter a Hipótese } \\
\text { nula }\end{array}$ \\
\hline 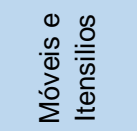 & $\begin{array}{l}\text { A Mediana das diferenças entre } \\
\text { VAR00001 e VAR00002 é igual a } 0\end{array}$ & $\begin{array}{l}\text { Teste dos Postos Sinalizados de } \\
\text { Wilcoxon de Amostras Relacionadas }\end{array}$ & 0,285 & $\begin{array}{l}\text { Reter a Hipótese } \\
\text { nula }\end{array}$ \\
\hline
\end{tabular}

São exibidas significâncias assintóticas. O nível de significância é de ,05.

Fonte: Elaborada pelos autores

Apenas os itens máquinas, equipamentos, edifícios e construções deram resultados abaixo de 0,05 , ou seja, hipótese nula. Os outros itens deram resultados superiores, na análise dos testes e no quadro 5 está detalhado melhor a análise dos resultados.

\subsubsection{Análise dos testes de Wilcoxon por Subgrupo de Ativos}

Conforme quadro abaixo, foi detalhado o subgrupo de ativos a analise conforme questionário respondido, apresentada na tabela 7: 
Tabela 7 - Análise dos testes aplicados

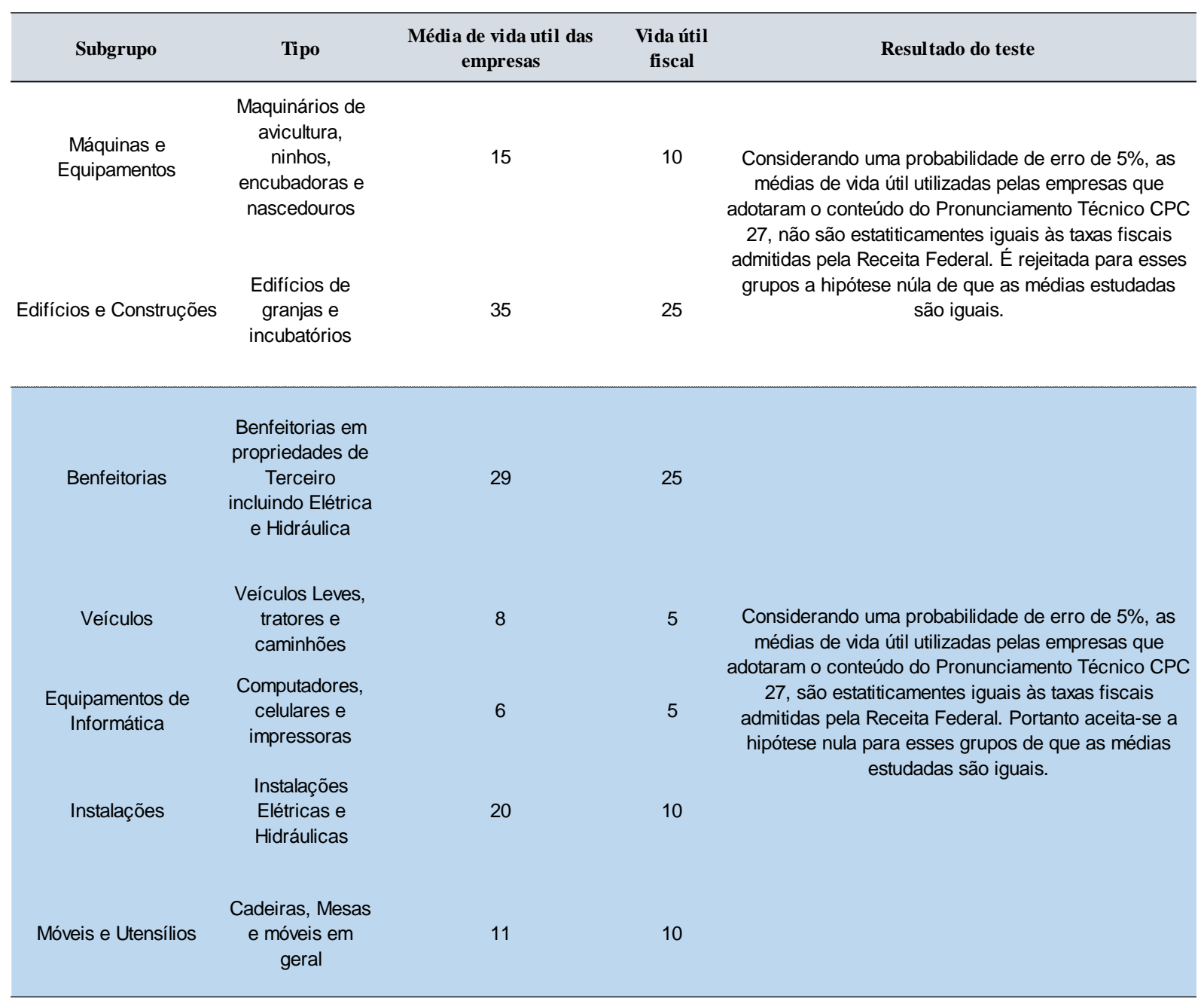

Fonte: Elaborado pelos autores

Nos subgrupos Máquinas e equipamentos, edifícios e construções foram utilizados prazos de vida útil que diferem significativamente dos prescritos pela legislação fiscal. No entanto, com relação aos subgrupos benfeitorias, veículos, equipamentos de informática, instalações e móveis e utensílios, foram utilizados prazos de vida útil, e consequentemente taxas de depreciação estatisticamente similares aos prazos de vida útil admitidos pela Receita Federal.

\section{CONSIDERAÇÕES FINAIS}

O presente estudo, teve por objetivo identificar se as empresas não listadas do setor de avicultura de frango de corte, estão aplicando o conceito de vida útil econômica de imobilizado para cálculo da depreciação. 
A amostra foi composta por 14 empresas do total de 40 questionários enviados. Deste total foram respondidos 18 e excluídos 4 por apresentarem respostas inconsistentes ou por terem questões sem respostas.

As demonstrações contábeis preparadas pela égide da estrutura conceitual objetivam fornecer informações contábeis relevantes e que seja representação fidedigna da realidade.

Mesmo após essa regulamentação, identificou-se que 57,14\% das empresas adotam o conceito de vida útil econômica de imobilizado para cálculo da depreciação para um total de 64,29\% de empresas classificadas como grande porte, ou seja, em relação à amostra, existem empresas de grande porte do setor estudado que optaram por manter taxas fiscais para cálculo da depreciação.

Em relação às empresas que adotam essa avaliação para cálculo da depreciação, utilizando intervalos médios informados, é possível observar que duas classes de imobilizado não apresentou variação expressiva em relação às taxas fiscais. Foi o caso da classe de Equipamentos de Informática, com vida útil média de 6 anos e 3 meses (vida útil fiscal 5 anos), e de Móveis e Utensílios, com vida útil média de 11 anos e 6 meses (vida útil fiscal 10). Todos os outros grupos apresentaram no mínimo uma diferença de 3 anos e 7 meses em relação às taxas fiscais.

Conforme resultado do teste de Wilcoxon, apenas os subgrupos de máquinas e equipamentos, e edifícios e construções mostraram que é possível rejeitar a hipótese nula, sendo assim aceitar o fato de que a vida útil contábil aplicada pelas empresas é significativamente diferente da taxa fiscal.

Apesar de estatisticamente alguns grupos do quadro 5 não mostrarem diferença significativa, é importante ressaltar que foi constatada vida útil econômica diferente da taxa fiscal, isso é positivo pois evidencia o uso da depreciação com base econômica e indica que ajustes ao lucro contábil são requeridos.

Comparando as respostas das questões 4 e 6, observou-se que um número maior de empresas, 57,1\% não ajustam valores decorrentes de depreciação por vida útil econômica e para fins ficais. Em relação ao número de 57,1\% que disseram utilizar taxas diferentes. Esse fato pode ser decorrente à utilização de laudo técnico de vida útil aceito pela Receita Federal ou decorrente de uma falha na apuração do lucro fiscal dessas empresas, informação não capturada no trabalho.

Para maioria dos entrevistados o custo inicial de sua aplicação e manutenção dos ajustes e práticas contábeis não superam os benefícios gerados da informação. 
Para o grupo da amostra do setor de avicultura, 42,86\% de empresas optaram por não utilizar o conceito de vida útil econômica e trabalhar com taxas fiscais, o que poderia afetar a comparabilidade quando se restringe ao setor. Ainda nesse sentido, 71,43\% dos entrevistados afirmaram que o tema apresentou impacto relevante nas demonstrações financeiras dessas empresas, e em mesmo número acreditam que sua não aplicação pode afetar negativamente a comparação entre o setor.

Apesar de sua importância e relevância, o alto custo inicial de sua aplicação e controles adicionais para ajustes fiscais, podem ter restringido sua aplicação por um número maior de empresas.

\section{REFERÊNCIAS}

Barbetta, P. A. (2014). Estatística aplicada às ciências sociais. 9. Ed. Florianópolis: Ed. Da UFSC.

Barth, M. E., Beaver, W. H., \& Landsman, W. R. (2001) The relevance of value relevance literature for financial accounting standard setting: another view. Journal of Accounting and Economics, v. 31, p. 77-104. http://dx.doi.org/10.1016/S01654101(01)00019-2

BRASIL (1976). Lei $\mathrm{n}^{\circ}$ 6.404, de 15 de dezembro de 1976. Dispõe sobre as Sociedades por Ações. Brasília, DF: Brasil. Disponível http://www.planalto.gov.br/ccivil_03/LEIS/L6404consol.htm. Acesso em: 20 de outubro de 2018.

BRASIL (2007). Lei $\mathrm{n}^{\circ} 11.638$, de 28 de dezembro de 2007. Altera e revoga dispositivos da Lei 6.404, de 15 de dezembro de 1976, e da Lei no 6.385, de 7 de dezembro de 1976, e estende às sociedades de grande porte disposições relativas à elaboração e divulgação de demonstrações financeiras. (2007). Brasília, DF: Brasil. Disponível em: http://www.planalto.gov.br/ccivil_03/_Ato2007-2010/2007/Lei/L11638.htm. Acesso em 21 de outubro de 2018.

CFC - Conselho Federal de Contabilidade (2005). Normas Brasileiras de Contabilidade. NBC T 19.5 - Depreciação, Amortização e Exaustão. Brasília, DF: Conselho Federal de Contabilidade.

CFC - Conselho Federal de Contabilidade (2005). Resolução no 1.055, de 07 de outubro de 2005. Dispõe sobre a criação do Comitê de Pronunciamentos Contábeis (CPC). Brasília, DF: Conselho Federal de Contabilidade. Disponível em: https://www.legisweb.com.br/legislacao/?id=101916. Acesso em 30 de outubro de 2018.

CFC - Conselho Federal de Contabilidade (2009). Pronunciamento Técnico CPC 27 - Ativo Imobilizado, de 26 de junho de 2009. Brasília, DF: Comitê de Pronunciamentos Contábeis.

Dornelles, D. S. (2011). CPC 27: os reflexos do novo tratamento contábil dos investimentos em ativo imobilizado. Porto Alegre. Disponível em: 


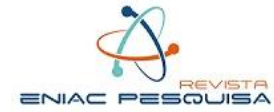

https://www.lume.ufrgs.br/bitstream/handle/10183/34993/000784621.pdf $>$. Acesso em 31.10.2018.

Gelbcke, E. R., Santos, A. dos, Iudícibus, S. de, \& Martins, E. (2018). Manual de Contabilidade Societária: Aplicável a Todas as Sociedades de Acordo com as Normas Internacionais do CPC. 3. Ed. São Paulo: Atlas.

Gil, A. C. (2008). Métodos e técnicas de pesquisa social. 6. Ed. São Paulo: Atlas.

Hendriksen, Eldon S., \& Van Breda, M. F. Teoria da Contabilidade. (1999). 5. ed, São Paulo: Atlas.

Hou, K., \& Robinson, D. T. (2006). Industry concentration and Average Stock Returns. The Journal of Finance, v. LXI, n 4, August.

Iudícibus, S. (2007). Teoria da Contabilidade. 11. ed, São Paulo: Atlas.

Marion, J. C. (2014). Contabilidade básica. 11. ed. São Paulo: Atlas.

Maroco, J. (2010). Análise Estatística com utilização do SPSS. 4. ed. Lisboa: Sílabo.

Martins, G. A., \& Teóphilo, C. R. (2016). Metodologia da investigação científica para ciências sociais aplicadas. 3. ed. São Paulo: Atlas.

Oliveira, A. B. S. (2011). Métodos da pesquisa contábil. (2011). São Paulo: Atlas.

Schmidt, P., Santos, J. L., \& Gomes, J. M. M. (2003). Contabilidade intermediária: atualizada pela minirreforma tributária: Lei $n^{\circ}$ 10.637/02. São Paulo: Atlas.

Souza, T. S. (2013). Taxas de depreciação de imobilizado antes e depois da adoção do CPC 27: uma análise das maiores companhias do país em vendas líquidas em 2012 que pertencem ao novo mercado da BM\&Fbovespa. (Trabalho de conclusão de curso de graduação). Pontifícia Universidade Católica de São Paulo, São Paulo.

Vergara, S. C. (2016). Projetos e relatórios de pesquisa em administração. 16 ed. São Paulo: Atlas.

Zanella, C. S., \& Sembraneli, S. T. (2016). Estudo da Aplicação do CPC 27 pelos escritórios de contabilidade de Quilombo/SC. Revista Conversatio, Xaxim - SC. Vol. 1, Número 1, Jan. a Jun. $2016 \quad$ p. $\quad 98 \quad-\quad-115 . \quad$ Disponível $\quad$ em: http://www.celer.com.br/revistaconversatio/edicao/01/artigo5.pdf $>$ Acesso em: 29 de outubro de 2018. 